\title{
O DIREITO E A INOVAÇÃO TECNOLÓGICA: OS (NOVOS) DESAFIOS DO EMPREGO DAS NANOTECNOLOGIAS
}

\author{
LAW AND TECHNOLOGICAL INNOVATION: THE (NEW) CHALLENGES OF \\ EMPLOYMENT OF NANOTECHNOLOGY
}

\author{
Augusto Zimmer Rodrigues** \\ Wilson Engelmann ${ }^{* *}$
}

\begin{abstract}
Resumo
A partir do advento das nanotecnologias a aplicação do conceito de inovação passa a ter uma importância significativa. Escolheu-se, para isso, a obra de Henry Etzkowitz, intitulada Hélice Tríplice: Universidade-Indústria-Governo, afim de averiguar a suficiência da proposta do autor. Outrossim, se verifica a necessidade de uma inovação no Direito, ou seja, um processo no interior da estrutura normativa diante dos novos desafios das tecnologias em escala nano, vez que essas transformações ocorrem de maneira muito rápida e com uma mínima participação das Ciências Humanas, incluindo o Direito.
\end{abstract}

Palavra-chave: nanotecnologias; inovação tecnológica; novos direitos; inovação radical.

\begin{abstract}
Since the advent of nanotechnology the application of the concept of innovation is to have a significant importance. Was chosen to do so, the work of Henry Etzkowitz, entitled Triple Helix: University-Industry-Government, in order to ascertain the sufficiency of the author's proposal. Therefore, there is a need for innovation in the law, in other words, a process within the regulatory framework in the face of new challenges of nano-scale technologies, because these changes occur very quickly and with minimal input of Human Sciences, including Law. Keywords: nanotechnology; technological innovation; new rights; radical innovation.
\end{abstract}

\footnotetext{
* Resultado parcial das investigações realizadas pelos autores no âmbito dos seguintes projetos: a) "Nanotecnologias aplicadas aos alimentos e aos biocombustíveis: reconhecendo os elementos essenciais para o desenvolvimento de indicadores de risco e de marcos regulatórios que resguardem a saúde e o ambiente (Rede Nanobiotec-Brasil/CAPES)"; e b) "As Nanotecnologias e o Direito: os Direitos Humanos como condição de possibilidade à regulamentação jurídica dentro de um cenário marcado pelo (novo) conceito de inovação $(\mathrm{CNPq}$ - Edital 014/2010 - Universal)".

** Graduando do Curso de Ciências Jurídicas e Sociais na Universidade do Vale do Rio dos Sinos - UNISINOS e membro do Grupo de Pesquisa JUSNANO. Tem experiência na área de Direito, com ênfase em Novos Direitos e inovações tecnológicas.

*** Graduado em Direito pela Universidade do Vale do Rio dos Sinos (1988), Mestre em Direito pela Universidade do Vale do Rio dos Sinos (2000) e Doutor em Direito pela Universidade do Vale do Rio dos Sinos (2005). Atualmente é professor da Universidade do Vale do Rio dos Sinos. Coordenador Adjunto do Programa de Pós-Graduação em Direito - Mestrado e Doutorado - da UNISINOS. Líder do Grupo de Pesquisa JUSNANO (CNPq/Unisinos). Avaliador ad hoc do INEP/DAES. Temas preferenciais: hermenêutica filosófica, ética, direito natural, direitos humanos, direitos fundamentais, nanotecnologias, inovação tecnológica, Lei do Bem, PADIS, transformações jurídicas nas relações privadas, constitucionalização do direito privado e metodologia da pesquisa jurídica. Orientador de bolsista de iniciação científica PIBITI/CNPq, PIBIC/CNPq e FAPERGS. Orientador de Mestrado e Doutorado.
} 


\section{Introdução}

As últimas décadas deixaram ainda mais visível o caráter transformador da espécie humana. Muito tem-se avançado no campo das novas tecnologias e as pesquisas dessas áreas têm evoluído em uma velocidade acelerada, resultando, pois, em novas e fascinantes descobertas. O momento presente indica um marco no avanço das nanotecnologias, ou tecnologias em pequeníssima escala, do mesmo modo, infinitas possibilidades despertam o interesse em converter tais aspetos inusitados em inovações tecnológicas, com o propósito de inseri-las ao mercado de consumo aperfeiçoando e qualificando as demandas produtivas.

Uma característica das evoluções tecnológicas, e é exatamente nesse sinal distintivo que repousa a necessidade de um aprofundamento reflexivo, é a que todos os seres vivos, incluindo seus habitats, podem, de alguma forma, estarem sujeitos direta ou indiretamente a ao produto dessas modificações, na medida de sua grandeza e complexidade. Isso explica a importância do estudo do tema. O Direito, todavia, tem como tarefa garantir o mínimo de sustentabilidade e proteção aos afetados dessas transformações advindas do campo das nanotecnologias. Para tanto, é imprescindível um olhar crítico, a fim de evitar, em nome do progresso, que a humanidade sofra novamente perdas irrecuperáveis. Este artigo pretende enfrentar e discutir o seguinte problema: em que condições o Direito poderá inserir-se no cenário de inovação alavancado pelas nanotecnologias?

Metodologicamente o artigo será construído a partir do método fenomenológicohermenêutico, por meio dos aportes alcançados por Martin Heidegger e Hans-Georg Gadamer. "A tarefa de se assegurar 'fenomenologicamente' o acesso ao ente exemplar como ponto de partida da própria analítica já se acha sempre delineada a partir do próprio ponto de chegada" (HEIDEGGER, 2002, p. 68, § 7). Esta perspectiva metodológica sinaliza à inserção no mesmo mundo onde o objeto e o pesquisador se situam, tanto do ponto de partida como o de chegada. O objeto de estudo deste artigo integra o mundo da vida, onde os seus autores também estão contemplados. Na análise fenomenológica do objeto o método já faz parte do objeto estudo, não sendo admitida a sua introdução de fora para dentro. Na conjugação desses 
fatores, o artigo pretende atribuir sentido ao tema, considerando que os resultados das nanotecnologias serão sentidos pelo grupo social, do qual os autores fazem parte. Nesse contexto, a partir de Heidegger a hermenêutica aponta para um caráter filosófico, deixando de ser metodológico-científica para ser ontológica. Por isso, filosofia hermenêutica. Já com Gadamer, a hermenêutica passa a ser substantiva, ganhando autonomia de área de conhecimento, pois arranjada a partir da experiência hermenêutica do sentido (ENGELMANN, 2007, p. 206-8).

A partir desse delineamento, este artigo pretende partir de algumas premissas diferentes das que normalmente orientam as pesquisas nas Ciências Humanas, dentre as quais se situa o Direito:

[...] nem a consciência do intérprete é senhora do que chega a ele como palavra da tradição, nem se pode descrever adequadamente o que tem lugar aqui, como o conhecimento progressivo do que, de maneira que um intelecto infinito conteria tudo o que, de um modo ou de outro, pudesse chegar a falar a partir do conjunto da tradição (GADAMER, 2002, p. 669, § 465).

É o movimento da tradição - da experiência, do já vivido, da aprendizagem com os fenômenos passados - que une o ponto de partida e o ponto de chegada descritos a partir da Heidegger. Portanto, o percurso da fenomenologia e da hermenêutica será orientado a partir do próprio acontecer do fenômeno das nanotecnologias na sociedade, desvelando-se como a condição de possibilidade para a produção da inovação do Direito. A linguagem assume um papel importante no delineamento do objeto, que escapa do controle do método: "[...] o fato de que a experiência hermenêutica se realize no 'modo' da linguagem, e que entre a tradição e seu intérprete tenha lugar uma conversação, coloca um fundamento completamente distinto. $\mathrm{O}$ decisivo é que aqui acontece algo" (GADAMER, 2002, p. 668-9, § 465). A proposta do estudo é focar na importância da linguagem para o seu desenvolvimento e não no método. E isso tem uma diferença significativa: “[...] visto a partir do intérprete, 'acontecer' quer dizer que não é ele que, como conhecedor, busca seu objeto e 'extrai' com meios metodológicos o que realmente se quis dizer e tal como realmente era, ainda que reconhecendo leves obstáculos e desvios, condicionados pelos próprios preconceitos" (GADAMER, 2002, p. 669, $\S 465)$. Essa mudança de ângulo fará com que a construção do conhecimento não seja alheia ao pesquisador/autor, mas parte integrante de sua existência, como "ser-no-mundo". Desta 
forma, “[...] o modo de ser da tradição, [...] é linguagem, e o ouvir que a compreende, na medida em que interpreta os textos, envolve sua verdade num comportamento para com o mundo, comportamento próprio e linguístico" (GADAMER, 2002, p. 671, § 467). A par das contribuições da filosofia no Direito, se pretende estudar a caracterização das nanotecnologias como um exemplo privilegiado de inovação e o modo como esse cenário influenciará a inovação na estruturação da construção do jurídico.

\section{Uma Análise da Inovação}

Inovação. Essa palavra é a derivação do termo latino innovatio, concebe uma ideia, método ou objeto que é criado e que se difere dos padrões anteriores. Hoje, a palavra inovação é empregada no contexto de aplicação de novas ideias que compreendem as implantações de produtos e processos tecnologicamente novos ou substanciais melhorias tecnológicas em produtos e processos (MANUAL DE OSLO, p. 54). Sabe-se que o desenvolvimento tecnológico e a inovação são essenciais para o elevação da produtividade, o que, por consequência, acarreta uma série de impactos econômicos, sociais e ambientais.

O século XX foi um marco à preocupação das questões da Inovação. No entanto, o crescimento de diversas fases ou ondas de inovação se projeta desde o Século XVIII, a partir da Revolução Industrial, conforme se pode verificar no gráfico a seguir reproduzido (BERGER, 2011):

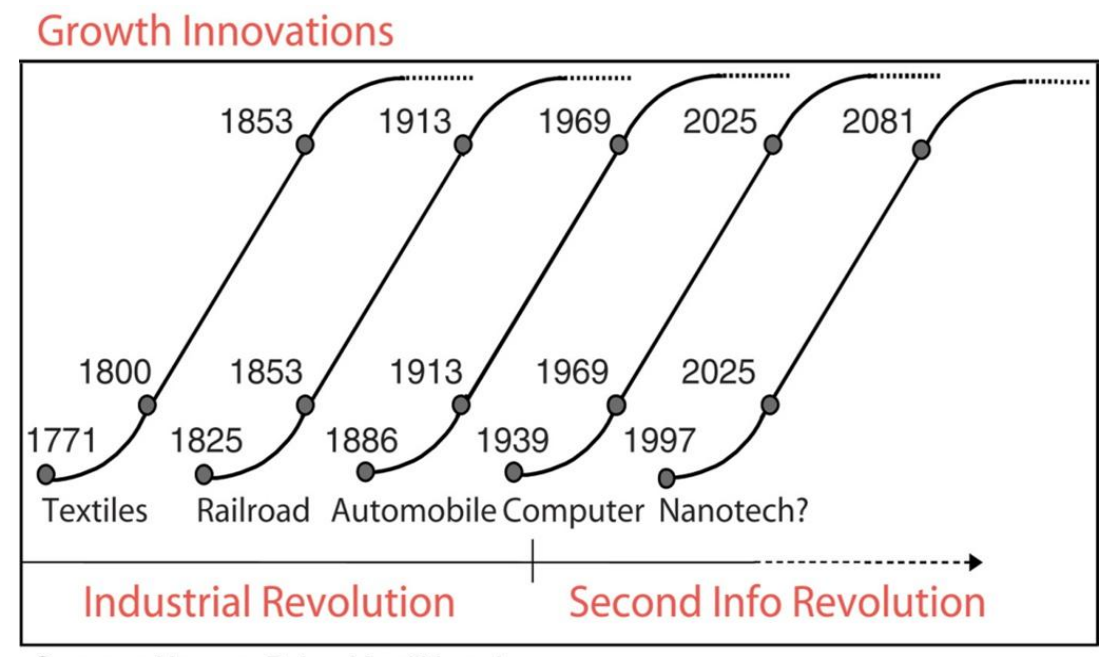

Sources: Norman Poire, Merrill Lynch 
O gráfico mostra o encadeamento de sucessivas ondas ou ciclos de Revoluções Industriais, destacando-se nas duas últimas ondas o incremento da Tecnologia da Informação e as Nanotecnologias (TIGRE, 2006, p. 65-6; FREEMAN e SOETE, 2000, p. 5-9; DICKEN, 2010, p. 92-8): 1) a primeira Revolução Industrial data de 1771 a 1853 (aproximadamente), a qual na parte relativa à ciência e tecnologia e educação se verificava o "aprender-fazendo; e o surgimento das sociedades científicas", ganham destaque os têxteis, maquinaria têxtil, trabalho/fundição com ferra, força hídrica, entre outros; 2) a segunda Revolução Industrial ocorrida entre os anos de 1825 a 1913 (aproximadamente), onde se verificou, no mesmo item, a educação voltada à formação de engenheiros mecânicos e civis; 3) a idade da eletricidade e do aço, ocorrida entre 1886 e 1969 (aproximadamente), com preponderância da pesquisa e desenvolvimento industrial, química e eletricidade, laboratórios nacionais; 4) idade da produção em massa - "Fordismo" - de automóveis e materiais sintéticos, datada de 1940 a 1990 (aproximadamente); 5) idade da microeletrônica, iniciada por volta de 1990 e ainda não concluída, se verifica o crescimento da rede de dados, redes globais de pesquisa e desenvolvimento; treinamento contínuo, aceleração da Tecnologia da Informação (mundo digital, Internet, Software, robótica). Esse "quinto ciclo deverá se esgotar à medida que a microeletrônica atingir patamares de difusão e as oportunidades de crescimento e de investimento começarem a declinar”. Em seu lugar, começa a ganhar força o sexto ciclo, caracterizado pelo "predomínio dos investimentos nas ciências da vida como motor de desenvolvimento": o avanço da biotecnologia e o trabalho "em novas dimensões subatômicas através da nanotecnologia". Constata-se, portanto, que se inicia uma nova Revolução Industrial, desafiando todos os padrões conhecidos até o momento, pois as nanotecnologias tratam da construção de coisas por meio do arranjo de átomos e moléculas, descendo à ordem de grandeza expressa na notação científica de $10^{-9}$. Essa sexta onda estará vinculada às tecnologias ambientais e de saúde. Pelo examinado até agora, vislumbra-se aqui uma abertura sem precedentes para enfrentar os problemas que caracterizam a sociedade como sendo de risco, especialmente as questões ambientais (ENGELMANN, 2011, p. 69-70).

Embora a inovação esteja presente em todas as ondas ou ciclos revolucionários, o embrião da concepção atual de inovação surgiu em 1948 com a Organização para a Cooperação Econômica (OECE), liderada por Robert Marjolin da França, para ajudar a 
administrar o Plano Marshall visando à reconstrução da Europa após a Segunda Guerra Mundial. Posteriormente a sua filiação foi estendida a estados não-europeus. Em 1961, a OECE deu origem à Organização para a Cooperação e Desenvolvimento Econômico, sua sede é localizada no Château de la Muette em Paris, França. A partir do artigo $1^{\circ}$ da Convenção, assinada em Paris no dia 14 de dezembro de 1960, e que entrou em 30 de dezembro de 1961, a Organização para a Cooperação e Desenvolvimento Econômico tem como enfoque promover as políticas destinadas a:

Conseguir a mais forte expansão sustentada da economia e do emprego e o aumento do nível de vida nos países membros, mantendo a estabilidade financeira e contribuindo assim para o desenvolvimento da economia mundial.

Contribuir para uma sólida expansão econômica nos países membros bem como não-membros em vias de desenvolvimento econômico.

Contribuir para uma expansão do comércio mundial numa base multilateral e nãodiscriminatória, conforme às obrigações internacionais (MANUAL DE FRASCATI, p. 10).

No mês de Junho de 1963, a OCDE organizou um encontro de peritos em estatísticas de Investigação e Desenvolvimento (ID) na Villa Falconieri de Frascati, na Itália. O resultado desse trabalho "foi a primeira versão oficial da Proposta de Práticas Exemplares para Inquéritos de Investigação e Desenvolvimento Experimental, mais conhecida como o Manual de Frascati” (MANUAL DE FRASCATI, p. 12). Ao longo dos anos o Manual sofreu alterações substanciais.

O Grupo de Peritos Nacionais em Indicadores de Ciência e Tecnologia (NESTI) desenvolveu, nos últimos períodos, uma série de manuais metodológicos com viés na Ciência e Tecnologia, conhecidos mundialmente como "Família Frascati", que compreende, entre outros manuais, o Manual de Frascati e o Manual de Oslo. Foi neste último manual, de forma geral, que se sustentaram as políticas de inovação das nações membros do OECD. Vale ainda ressaltar que dentre os objetivos da OECD destacam-se a preocupação em alcançar o mais alto nível de desenvolvimento econômico sustentável e de emprego a contribuição para a expansão econômica estável em todos os países (MANUAL DE FRASCATI, p. 12).

Como desdobramento deste Manual, é elaborado o Manual de OSLO, cuja primeira edição data 1990 e também foi desenhado pela Organização para Cooperação e 
Desenvolvimento Econômico. É a principal fonte internacional de diretrizes para coleta e uso de dados sobre atividades inovadoras da indústria.

A capacidade de determinar a escala das atividades inovadoras, as características das empresas inovadoras e os fatores internos e sistêmicos que podem influenciar a inovação é um pré-requisito para o desenvolvimento e a análise de políticas que visem incentivar a inovação tecnológica.

Para o Manual de OSLO “inovações tecnológicas em produtos e processos compreendem a implantação de produtos e processos tecnologicamente novos e substanciais melhorias tecnológicas em produtos e processos. Uma inovação TPP é considerada implantada se tiver sido introduzida no mercado (inovação de produto) ou usada no processo de produção (inovação de processo). Uma inovação TPP envolve uma série de atividades científicas, tecnológicas, organizacionais, financeiras e comerciais. Uma empresa inovadora em TPP é uma empresa que tenha implantado produtos ou processos tecnologicamente novos ou com substancial melhoria tecnológica durante o período em análise” (MANUAL DE OSLO, 2011. O grifo está no original).

Em 2006 foi elaborada a terceira edição do Manual de OSLO, onde se verifica o seguinte conceito: uma inovação é a implementação de um produto (bem ou serviço) novo ou significativamente melhorado, ou um processo, ou um novo método de marketing, ou um novo método organizacional nas práticas de negócios, na organização do local de trabalho ou nas relações externas (MANUAL DE OSLO, 2011). A nova edição traz um conceito com modificações e a inclusão das atividades de marketing, dentre aquelas que poderão gerar inovação.

Deste modo, o Manual de Oslo se consolidou como a principal fonte internacionalizada de diretrizes para uso de dados sobre atividades inovadoras na indústria. Segundo o Manual de Oslo, a Inovação pode ocorrer em qualquer setor da economia, incluindo serviços governamentais como saúde e educação, isso explicaria a importância do estudo e da utilização do processo Inovador para fomentar o crescimento econômico e a 
melhoria da qualidade de vida. Além disso, ele "[...] na encara a inovação apenas como uma fonte de ideias, mas principalmente como um 'solucionador de problemas' em qualquer etapa do processo produtivo (TIGRE, 2006, p. 87). A inovação não é mais apenas o processo de criação, mas também de aplicação, manifestando-se “[...] como um processo simultâneo de mudanças envolvendo uma diversificada gama de atividades internas e externas à empresa" (TIGRE, 2006, p. 87).

Pode-se afirmar que o gerador base do mecanismo de uma economia capitalista vem "dos novos produtos de consumo, dos novos métodos de produção e transporte, dos novos mercados, das novas forças da organização industrial que o empreendimento capitalista gera" (DICKEN, 2010, p. 117). A inovação baseia-se nessas perspectivas, eis que ela é a criação e difusão de novas maneiras de fazer as coisas, no escopo dos processos de crescimento e desenvolvimento econômicos. (DICKEN, 2010, p. 117) Não resta dúvidas que as mudanças tecnológicas são fundamentais para formar padrões de transformação da economia. A forma de gerir essa estratégia de inovação, em outras palavras, a gestão de inovação, pode ser explicada como uma abordagem que ajuda o tomador de decisão da empresa em nível estratégico a organizar o processo de geração de inovações, renovação da empresa, geração de novos negócios fomentados pelo processo de inovação.

Um aspecto é importante a ressaltar: Inovação é o âmago da mudança tecnológica - "é fundamentalmente um processo de aprendizagem. Essa aprendizagem - 'fazendo', 'usando', observando e compartilhando com outras pessoas - depende do acúmulo e desenvolvimento do conhecimento (...)” (DICKEN, 2010, p. 117). Dentro desse cenário, é preciso verificar se as nanotecnologias poderão ser consideradas uma efetiva inovação, aspecto que será examinado ao longo deste artigo. Ao lado disso, também será interessante verificar se a inovação é incremental ou radical. A primeira categoria abrange "[...] modificações progressivas, em pequena escala, de produtos e processos já existentes, criadas através dos métodos de 'aprender fazendo' e 'aprender usando'” (DICKEN, 2010, p. 92). Já a segunda categoria relaciona-se a "[...] eventos descontínuos que alteram drasticamente produtos ou processos já existentes. Entretanto, uma única inovação radical não surtirá um efeito abrangente sobre o sistema econômico; para isso, é necessário um 'grupo' dessas 
inovações" (DICKEN, 2010, p. 93). O incremento é um melhoramento; a radicalidade inovativa é algo novo, ainda não existente.

A Constituição Federal de 1988, especificamente nos artigos 218 e 219, trata da ciência e tecnologia. Este tema se encontra sob o título da Ordem Social, merecendo ser sublinhado que "o Estado promoverá e incentivará o desenvolvimento científico, a pesquisa e a capacitação tecnológicas" (caput, do art. 218). Verifica-se, portanto, que a estruturação da Ordem Social brasileira também está alicerçada na promoção da pesquisa científica e no desenvolvimento do parque tecnológico. Há uma subdivisão da pesquisa: a) a pesquisa científica básica, que receberá tratamento prioritário, considerando-se um bem público e lastreada no progresso da ciência (art. 218, § $1^{\circ}$ ); b) a pesquisa tecnológica, que apresenta um foco bem definido: a solução de problemas brasileiros, além do "desenvolvimento do sistema produtivo nacional e regional" ( $§ 2^{\circ}$, do art. 218). Pode-se mencionar que a pesquisa básica é uma forte alavanca para o desenvolvimento da pesquisa tecnológica. Não se trata de uma cisão, mas de dois componentes fundamentais para o progresso científico brasileiro. $\mathrm{O}$ aspecto criativo é destacado, na medida em que não se pensa na importação de um modelo, mas na sua criação, adequando-o às necessidades do Brasil, bem como o respeito às peculiaridades de cada região nacional.

No Brasil, há diversos organismos vinculados à questão da Inovação, em observância ao Decreto 7.096, de 4 de fevereiro de 2010, ficou a Secretaria de Inovação competente, entre outras atribuições, contribuir para a formulação da Política de Desenvolvimento, Indústria e Comércio Exterior nos aspectos relacionados à inovação e à política tecnológica, para o desenvolvimento sustentável nos sistemas produtivos. Além disso, cabe à Secretaria da Inovação planejar, estabelecer, supervisionar, coordenar, avaliar e controlar políticas, estratégias, atividades e recursos referentes a inovação tecnológica nos sistemas produtivos e tecnologias inovadoras e estratégicas (MDIC, 2011).

Neste tema deve ser destacada a atuação do Ministério da Ciência, Tecnologia e Inovação (MCTI) que foi criado pelo Decreto 91.146, em 15 de março de 1985, concretizando o compromisso do presidente Tancredo Neves com a comunidade científica nacional. Sua área 
de competência está estabelecida no Decreto n ${ }^{\circ}$ 5.886, de 6 de setembro de 2006. Como órgão da administração direta, o MCTI tem como competências os seguintes assuntos: política nacional de pesquisa científica, tecnológica e inovação; planejamento, coordenação, supervisão e controle das atividades da ciência e tecnologia; política de desenvolvimento de informática e automação; política nacional de biossegurança; política espacial; política nuclear e controle da exportação de bens e serviços sensíveis (MCTI, 2011).

Especificamente no tocante às nanotecnologias, cabe sublinhar as atividades desenvolvidas pelo Fórum de Competitividade em Nanotecnologia, coordenado pelo Ministério do Desenvolvimento, Indústria e Comércio Exterior: O Fórum surge como ferramenta estratégica para apoiar a discussão e encaminhamento de iniciativas e programas segundo as dimensões da Política de Desenvolvimento Produtivo. Tem como objetivo aumentar a competitividade do país no mercado mundial por meio da articulação entre as necessidades do setor privado - formado por representantes do meio empresarial e dos trabalhadores - o setor governamental e a academia. O Fórum busca o consenso em torno de oportunidades e desafios, definindo metas e ações voltadas para uma nova política industrial de desenvolvimento da produção (FÓRUM DE COMPETITIVIDADE, 2011). As atividades do Fórum são distribuídas entre os seguintes Grupos de Trabalho: Marco Regulatório, Mercado, Formação de Recursos Humanos e Cooperação Internacional; além de um Núcleo Empresarial.

As rápidas transformações e o aumento da complexidade da sociedade moldaram o Estado de tal forma que além de sua função repressora e garantidora, ele passa a aparecer "muito mais como produtor de serviços de consumo social, regulamentador da economia e produtor de mercadorias" (FERRAZ JR, 2010, p. 59). Diante desses aspectos, observou-se a necessidade de implantação de políticas de estratégia de Inovação não apenas nos países membros do OECD, uma vez que o Brasil já possui material, inclusive normativo, produzido acerca do assunto. O legislador brasileiro preocupou-se em estabelecer as relações do Manual de Oslo no território nacional, almejando impulsionar a Inovação e garantir benefícios aos empreendedores e a 
própria sociedade, vez que assim existe a possibilidade de geração de empregos ao beneficiar a indústria local.

Nos termos da Lei $\mathrm{n}^{\mathrm{o}} 10.973$, de 02 de dezembro de 2004, mais conhecida como "Lei da Inovação", que estabelece "medidas de incentivo à inovação e à pesquisa científica e tecnológica no ambiente produtivo" (art. $1^{\circ}$, caput), se constata: “inovação: introdução de novidade ou aperfeiçoamento no ambiente produtivo ou social que resulte em novos produtos, processos ou serviços" (art. $\left.2^{\circ}, \mathrm{IV}\right)$. A Lei de Inovação Tecnológica está dividida em três esferas: a constituição de ambiente inovador que propicie a relação entre os centros acadêmicos e empresas; o estímulo à participação de instituições de ciência e tecnologia no processo de inovação; e o incentivo à inovação na empresa. Ela dispõe sobre autorizações para a incubação de empresas no espaço público e a possibilidade de compartilhamento de infra-estrutura, equipamentos e recursos humanos, públicos e privados, para o desenvolvimento tecnológico e a geração de processos e produtos inovadores. A Lei de Inovação Tecnológica também autoriza o aporte de recursos orçamentários diretamente à empresa, no âmbito de um projeto de inovação, sendo obrigatórias a contrapartida e a avaliação dos resultados. São ainda instrumentos desta lei a encomenda tecnológica, a participação estatal em sociedade de propósito específico e os fundos de investimentos (PEREIRA, 2005, p.11).

Com o intuito de viabilizar a Lei da Inovação, o Governo Federal fundou a Agência Brasileira de Desenvolvimento Industrial (ABDI). A agência é responsável pela execução e fiscalização das políticas do escopo industrial e tecnológicas. Além disso, a ABDI tem como função articular ações e estratégias da política industrial por meio do apoio ao desenvolvimento do processo de inovação e do fomento à competitividade do setor produtivo (PEREIRA, 2005, p. 11). Ligada ao Ministério do Desenvolvimento, Indústria e Comércio Exterior (MDIC), atua como elo entre o setor público e privado, contribuindo para o desenvolvimento sustentável do País por meio de ações que ampliem a competitividade da indústria. (ABDI) 
Outro texto normativo que merece destaque é a Lei ${ }^{\circ} 11.196$, de 21 de novembro de 2005, chamada de "Lei do Bem", recebe esse nome pois institui benefícios fiscais para as empresas inovadoras, considera "inovação tecnológica a concepção de novo produto ou processo de fabricação, bem como a agregação de novas funcionalidades ou características ao produto ou processo que implique melhorias incrementais e efetivo ganho de qualidade ou produtividade, resultando maior competitividade no mercado" (art. 17, $\S 1^{\circ}$ ). A lei se destina, resumidamente, a todas as empresas que investem em inovação, e parte dos gastos é direcionado ao abatimento de Imposto de Renda e Contribuição Social sobre o Lucro, as maiores beneficiadas são as empresas que optam pelo chamado Lucro Real. Sobre a efetividade da lei, é constatado que muitas empresas ainda não utilizam os recursos e benefícios da Lei do Bem, o maior motivo é a falta de conhecimento. "Pode-se citar outros fatores, mas que ainda preservam relação com este: falta de assessoria especializada, que não deixa de ser falta de conhecimento; medo do fisco; dúvidas quanto à interpretação da Lei e demora na decisão interna" (INSTITUTO INOVA).

$\mathrm{Na}$ esfera estadual também existem exemplos normativos tratando do assunto. $\mathrm{O}$ Rio Grande do Sul, por meio da Lei $\mathrm{n}^{\circ}$ 13.196, de 13 de julho de 2009, estabeleceu as medidas de incentivo à inovação e à pesquisa científica e tecnológica, foi o décimo Estado da Federação a adotar tais medidas. A referida lei considera como inovação a "introdução de novos produtos, processos, serviços, marketing ou inovação organizacional, bem como aperfeiçoamento dos já existentes, no ambiente produtivo ou social visando ampliar a competitividade da empresa no mercado local ou global e melhorar as condições de vida da sociedade do Rio Grande do Sul” (art. 2º, I). Fica explícita, assim, a preocupação do legislador rio-grandense, no texto da lei, para com a melhoria do padrão social do povo gaúcho.

Na busca pelo desenvolvimento econômico e social, a Lei do Bem e a Lei da Inovação aparecem como elementos catalisadores fundamentais para a criação de um ambiente onde é dado prioridade a ações que promovam suas próprias características de mercado, agregando maior valor à produção, gerando emprego e renda. A diversificação da matriz produtiva e a integração total dos setores público e privado com as universidades 
regionais têm papel determinante neste processo. Este é o modelo a ser perseguido, ou seja, de aproximação da academia com o setor privado, como se verá a seguir.

A inovação se tornou rapidamente escopo para os mais diversos segmentos do conhecimento e parece cada vez mais estar sendo fomentada pelos meios de comunicação. Não há dúvidas dos benefícios que todas as modificações inovadoras nos produtos e processos possam trazer. Embora o campo para essas transformações seja muito promissor, pouco se questiona até onde há limites para operar a transformação, ou se há limites para tanto. O que muito se tem a ser percebido até então é a mera preocupação econômica, há a necessidade, portanto, de rever tais tomadas e focar os esforços para os destinatários das inovações.

\section{Hélice Tríplice e o Modelo Inovador}

A própria ação de inovar pode seguir métodos para garantir sua melhor efetividade e resultado. Seguindo essa linha, a proposta de Etzkowitz é conectar diferentes entidades com o propósito de gerar inovação e outros benefícios para com os grupos que dela participam. Isso foi possível com a alteração do paradigma da sociedade industrial para o da sociedade do conhecimento, que trouxe o saber e a sua gestão no centro de uma ampla discussão, envolvendo o Estado, a iniciativa privada, ou o empreendedorismo e a universidade. A crescente necessidade de conhecimentos científicos para o progresso técnico e celeridade da Inovação exigem práticas de cooperação tecnológica entre os atores envolvidos no processo de geração e difusão de inovações, a chamada hélice tríplice. No Brasil, um bom exemplo são os Editais das agências de fomento como o CNPq e a FAPERGS que promovem o chamado "pesquisador na empresa".

Sob um prisma alicerçado na teoria do Prof. do MIT (Massachusetts Institute of Technology), Henry Etzkowitz, em sua obra intitulada Hélice Tríplice, pode-se dizer, em uma primeira análise, que a inovação é a interação entre Universidade, Indústria e Governo. Ao analisar essa afirmação já é possível prever a grande complexidade das interconexões advindas dessas três grandes corporações. O livro é introduzido com a afirmação que "a 
interação entre universidade, indústria e governo é a chave para inovação e o crescimento em uma economia baseada no conhecimento" (ETZKOWITZ, 2009, p. 1). Deste modo a “universidade é o princípio gerador das sociedades fundadas no conhecimento, assim como o governo e indústria são as instituições primárias na sociedade industrial” (ETZKOWITZ, 2009, p. 1).

A passagem deixa claro que o cenário científico e industrial passa por alterações profundas, o que quer dizer que o modelo tradicional de uma sociedade puramente industrial está se mostrando ineficaz. É de se alertar que "nos últimos anos, estamos experimentando uma nova revolução, em marcha no mundo todo: a da indústria do conhecimento. Esse fenômeno está tomando corpo e envolvendo cada vez mais um grande número de nações, inclusive o Brasill". Em sintonia com esse processo, "os países que lideram a produção de novos conhecimentos, sua aplicação e transformação em produtos preocupam-se mais em criar do que em produzir. De certo modo, é a continuidade das ondas de inovação que, por exemplo, permitiram à Europa a Revolução Industrial e que agora preparam a Revolução do Conhecimento" (PRODANOV, 2011).

O processo de produção passou por diversos estágios, conforme se verificou na primeira parte deste artigo. Sua trajetória foi gradativa e serviu como fundador para muitas reivindicações sociais e trabalhistas, que originaram grandes revoluções e modificações na vida civil. A Revolução Industrial foi a grande propulsora dessas alterações. Pelos aspectos já vistos, a Revolução das Nanotecnologias gerará profundas mudanças na sociedade e o tripé Universidade, Indústria e Estado poderá promover uma percepção de que uma sociedade baseada no conhecimento opera com dinâmicas diferentes daquelas adotadas em uma sociedade puramente industrial. Por conta disso, as economias fundadas nessa representação estão em constante modificação, não ficando estagnadas e presas a determinados modelos, em outras palavras, a sociedade baseada no conhecimento "está sujeita à contínua transformação, ao invés de estar arraigada a arranjos estáveis" (ETZKOWITZ, 2009, p. 7). Deste modo, a inovação é a nova configuração de elementos que combinam e geram um maior índice de produtividade. 
A inovação, na perspectiva da Hélice Tríplice, assume um novo significado quando ocorre o entrelaçamento das espirais, pois ela não é mais um campo de ação especial da indústria. Destarte, o regime da hélice tríplice começa quando a Universidade, a Indústria e o Estado dão início a um relacionamento recíproco, no qual cada um tenta melhorar o desempenho do outro. Esta interação entre diferentes agentes sociais torna-se claramente necessária quando estudamos a conjectura do mercado atual, onde a demanda é gerada na inovação do conhecimento. Sendo assim, cada uma das três Hélices precisa estar conectada e aberta para as interações necessárias, a fim de gerar a capitalização do conhecimento. Esse último significa dizer que o conhecimento é criado e transmitido para o uso, ou colocar o conhecimento em prática, destarte, isso é a "base para o desenvolvimento econômico e social e, assim, de um papel aprimorado da Universidade na sociedade" (ETZKOWITZ, 2009, p. $57)$.

Doravante, a Universidade assume papel fundamental no movimento das hélices, a de "conectar-se aos usuários de conhecimento de forma mais próxima" e "estabelecer-se como autor econômico por mérito próprio." Esse é o modelo de uma universidade empreendedora, que busca "achados de pesquisa com potencial tecnológico e os coloca em prática" (ETZKOWITZ, 2009, p. 37). O autor exemplifica a situação do Brasil, uma vez que aqui se tem "desenvolvido esse potencial mais claramente através de projetos de incubadoras direcionadas a inclusão social", pois aqui o "potencial da incubadora vai muito além da alta tecnologia, e até mesmo da empresa de negócios", visto que "o processo da incubadora se tornou um meio de desenvolver a relação da universidade em setores até então excluídos da sociedade" (ETZKOWITZ, 2009, p. 40). A principal razão para essa ampliação do papel da Universidade, para além do ensino, foi o custo-benefício. Verificou-se que "combinar pesquisa com ensino era muito menos caro do que manter instituições separadas para cada propósito" e "o conhecimento gerado pela pesquisa do corpo docente concede relevância e vitalidade de seu ensino" (ETZKOWITZ, 2009, p. 56).

Acerca da Indústria, ou da empresa, o administrador Henry Etzkowitz ressalva a importância da gestão dessa instituição, coloca a organização empresarial centro da estratégia de inovação. O que ocorre com frequência é empresas de grande porte transferindo unidade de 
pesquisa para colaborar de forma mais próxima com grupos de pesquisa acadêmica para desenvolver novos produtos, assim como para recrutar e observar descobertas com implicações comerciais. A cooperação entre os atores industriais, acadêmicos e governamentais pode vir a ampliar as inovações "chegando a um novo modo de produção dentro de uma região, no seio de um sistema de inovação nacional ou até de forma mais abrangente" (ETZKOWITZ, 2009, p. 61). Com esta mudança, será possível enfrentar a lacuna ainda muito presente entre a produção acadêmico-científica e a sua transferência às indústrias. Este ainda é um grande gargalo não apenas brasileiro. Romper com esta falta de comunicação, edificando pontes de aproximação poderá ser uma chave interessante para o desenvolvimento e o crescimento econômico-social.

O Estado, por sua vez, participa do movimento inovador, de acordo com seu modelo estatal. Aqui cabe uma pequena alteração, opta-se por adotar "Estado", ao invés de "Governo", pois aquele é mais perene e duradouro, ao passo que esse é periodicamente transitório em muitos países. O Estado assumindo sozinho o papel de coordenação integral da hélice tríplice fornece uma fonte limitada de iniciativas e essa não é a maneira mais produtiva de relacionamentos da hélice tríplice. Caso houver contribuição industrial e acadêmica, "então há uma base muito maior para desenvolver idéias criativas para a inovação, bem como uma base melhor para a implementação, especialmente em nível regional e local." (ETZKOWITZ, 2009, p. 87)

No território brasileiro, na década de 1970 ocorreu a primeira "revolução acadêmica", ou seja, "a incorporação da pesquisa como grande missão da universidade", acarretando, então, a ampliação da função acadêmica na "sociedade de uma estrutura de apoio tradicional para uma estrutura diretamente ligada às prioridades nacionais". Isso ocorreu sob o regime militar, e a universidade tinha "relativa autonomia". (ETZKOWITZ, 2009, p. 88)

A relação da hélice tríplice convertida em um estado de inovação é conceituada como regeneradora de fontes de produtividade em ciência e tecnologia através de novas formas de relações de cooperação. Assim, os preceitos básicos de um estado de inovação são 
descritos em uma série de propostas sobre a transformação das funções do Estado tradicional para promover a inovação, segundo Henry Etzkowitz, são os seguintes:

“1. A criação de uma autoridade legítima dentro de um território é estendida da esfera pública ao setor privado, promovendo a estabilidade e reduzindo a incerteza na interação" (ETZKOWITZ, 2009, p. 103). Aqui se verifica claramente a superação parcial da dicotomia entre o público e o privado, com o surgimento das bases para o espaço social.

"2. A cobrança de impostos para apoiar a proteção da nação e a promoção do bemestar social geral é ampliada utilizando o sistema fiscal de forma direcionada para fornecer incentivos e benefícios fiscais" (ETZKOWITZ, 2009, p. 103). Aqui se abre o espaço para a inserção promocional do Direito, apontada por Norberto Bobbio: “[...] a concepção tradicional do direito, partindo da consideração da ordem como fim dele, sempre viu na ameaça de sanções negativas, como penas, multas, reparações, ressarcimento de danos, etc., o instrumento com o qual ele persegue o seu fim" (BOBBIO, 2007, p. 99). Embora a função promocional já tenha sido defendida por Bobbio num texto publicado em 1969, na atualidade, sob o império das nanotecnologias, ela se mostra como uma possibilidade de inovação no Direito: “[...] quando o Estado pretende encorajar certas atividades econômicas (e não apenas econômicas), vale-se, cada vez com maior frequência, do procedimento do incentivo ou do prêmio, isto é, do procedimento da sanção positiva" (BOBBIO, 2007, p. 100-1). Esta função positiva, promocional e incentivadora de atitudes positivas, voltadas à promoção e o desenvolvimento da inovação é um aspecto fundamental da renovação do Direito e seu alinhamento com os novos desafios lançados à sociedade pela Revolução das Nanotecnologias.

3. Criação de regras para apoiar a vida econômica, inclusive a criação de leis para licenciar empresas e fundações para regulamentar o comportamento dos mercados e dos sistemas de moeda.

4. Utilização do sistema jurídico para criar direitos especiais, tais como patente e monopólios temporários para promover a inovação (ETZKOWITZ, 2009, p. 103).

Aqui se verifica claramente a importância dos marcos regulatórios para incrementar o desenvolvimento da inovação. Tal aspecto é confirmado em recente estudo promovido pela ABDI, acerca das condicionantes do futuro do desenvolvimento da 
nanotecnologia no Brasil, onde se verifica a necessidade de "legislação, risk assessment institucionalizado, valores em relação ao uso das nanotecnologias; regulamentação técnica e metrologia vinculadas a elas" (ABDI, 2010, p. 44).

“5. Oferta de financiamento para pesquisa básica a fim de criar um modelo linear de inovação" (ETZKOWITZ, 2009, p. 103).

Os cinco pontos deixam clara a preocupação do autor no campo da efetividade dessa Teoria da Inovação. Fica nítido a necessidade de adotar medidas políticas, afim de assegurar o resultado da interação das entidades entrelaçadas. A cobrança de tributos torna o cidadão sujeito da inovação, e, deste modo, poderá ter direitos em exigir a efetiva abordagem da hélice na sua localidade e a ampliação do bem-estar social. Vale ressaltar que o Poder Legislativo e o Poder Judiciário tem a tarefa, segundo o autor, de estabelecer leis que orientem e possibilitam licenças às empresas, e estabelecer direitos especiais que promovam a Inovação, com a finalidade de viabilizar e impulsionar o movimento das hélices. Isso coloca o Direito relacionado diretamente com o modelo inovador que se busca a partir da adoção da Hélice-Tríplice, então ,não se pode contestar, sob esse olhar, que a Inovação possui certa dependência com o Sistema Judiciário.

Por conseguinte, a forma ideal da hélice tríplice é aquela em que as três esferas interagem e cada uma assume o papel das outras, sendo que as iniciativas surgem lateralmente bem como de baixo para cima e de cima para baixo. Todas as entidades competentes devem estar conexas na relação de Inovação para o que se demonstra um modelo eficaz de inovar. Não se pode esquecer que "a sociedade civil é a base da hélice tríplice e da relação entre política científica e democrática", de modo que "a hélice tríplice completa ocorre em uma sociedade democrática onde as iniciativas possam ser livremente formuladas" (ETZKOWITZ, 2009, p. 104). A Tríplice Hélice é, em termos gerais, a busca de um diálogo cada vez mais intenso entre as instituições produtoras de bens de conhecimento e as produtoras de bens e serviços, a fim de gerar a interação entre pesquisadores, agentes econômicos, grupos sociais, indivíduos e órgãos estatais, configurando um ponto de 
convergência entre as potencialidades científicas e as necessidades econômicas e sociais. Esta também é a linha de percurso traçada e incentivada pelo Manual de OSLO.

\section{Nanotecnologia um Exemplo de Inovação (?)}

A partir da caracterização da inovação e uma teoria do que demonstra ser a mais eficiente para colocá-la em prática, torna-se imprescindível usar-se do exemplo das nanotecnologias afim de averiguar se estas se enquadram no conceito de inovação, já que muito tem-se fomentado acerca dessas novas tecnologias. As áreas duras do conhecimento estão, em grande velocidade, produzindo e formulando novos materiais que se utilizam da nanotecnologia para agregar novas propriedades. O problema é que todas essas transformações ocorrem de maneira muito rápida e com uma irrisória participação das Ciências Humanas. Este é o caso do Direito que tem contribuído muito pouco para assegurar um mínimo de respeito à dignidade humana e à integridade ambiental. Embora se pense que a solução é criar leis, dois aspectos desse pensamento devem ser salientados: ao criar uma lei, o legislador poderia estar engessando o conceito de nanotecnologia não permitindo seu pleno desenvolvimento, pois o estudo e a aplicação nessa área da ciência estariam fechados por critérios normativos preestabelecidos e a partir de pressupostos científicos ainda parcialmente conhecidos; o segundo aspecto é a validade fática destas leis, que poderá esbarrar na falta de condições técnicas de atuação, como a falta de infra-estrutura laboratorial, mão-de-obra especializada, insumos, definição de métricas, metodologia para a aferição da nanotoxicidade e a gestão do risco.

O início da referência ao tema, ainda que não utilizado o termo Nanotecnologia, deu-se em uma palestra ocorrida 1959, realizada pelo físico Richard Feynman. Foi em sua apresentação intitulada "There is plenty of room at the bottom”, (Há muito espaço lá em baixo) que Feynman propôs os métodos a fim de desenvolver a capacidade de manipulação atômica e molecular. O físico expressa: "Os princípios da física não falam contra a possibilidade de se manipular as coisas átomo por átomo". Feynman argumenta a existência de tanto lugar nessa mínima escala que, uma vez compreendida e aplicada a manipulação dos átomos individualmente, seria lançada a possibilidade de registro de tudo o que a humanidade 
escreveu até a presente data em algo com dimensões de um grão de poeira (FEYNMAN, 2011).

O termo Nanotechnology surgiu em 1974, na Universidade de Ciências de Tókio, o responsável foi o professor Norio Taniguchi, que utilizou-se da expressão para descrever a manufatura precisa de materiais com tolerâncias nanométricas. Na década seguinte, o termo foi revisto e sua definição ampliada pelo professor K. Eric Dexler do Massachusetts Institute of Technology - MIT, em seu livro "Engines of Creation - The Coming Era of Nanotechnology", de 1986. Em sua tese de doutorado "Nanosystems: Molecular Machinery, Manufacturing and Computation", publicado em 1992, foi reacendido o interesse pela tecnologia no meio cientifico mundial (INSTITUTO INOVAÇÃO).

O conceito de nanotecnologia ainda não encontra um caráter absoluto e universal, podendo variar em suas formulações. Entretanto, o relatório do ISO TC 229 - principal órgão mundial de padronização - define nanotecnologia, dois itens são de interesse, o primeiro expressa que essas tecnologias são "entendimento e controle de matéria e processos em nano escala, tipicamente, mas não exclusivamente, abaixo de 100 nanômetros em uma ou mais dimensões, onde o aparecimento de fenômenos dependentes de tamanho geralmente permite novas aplicações"; o segundo item dispõe que nanotecnologia é a utilização de propriedades em materiais na nanoescala que diferem da propriedade individual dos átomos, moléculas e massa para criação de matéria, utensílios e sistemas que exploram essas novas propriedades" (ISO TC 229). A passagem deixa claro o potencial das nanotecnologias como inovação, eis que elas favorecem propriedade totalmente novas nos produtos e processos, possibilitando, entre outras características, produtos mais resistentes, leves, assépticos e viáveis.

Entre os atuais avanços tecnológicos, devida suas peculiaridades e campo de possibilidades promissor, um deles merece devida atenção, são as tecnologias em escala nano. Essas tecnologias expressam um conjunto de "técnicas multidisciplinares", com dimensões espaciais que variam em valores aproximados de 1/10 mícron, ou cem bilionésimos de metro (NEUTZLING, 2009, p. 56) cumpre dizer, um nanômetro é a bilionésima parte de um metro, algo invisível para os olhos humanos. Para melhor entendimento da pequeneza dessa escala, 
deve-se dividir um metro em um bilhão de vezes, a bilionésima parte desse um metro é um nanômetro, e as nanotecnologias giram em torno de 100 nanômetros, repetindo: "tipicamente, mas não exclusivamente", conforme o ISO TC 229.

Sugere-se a revisão do termo multidisciplinaridade, referida por Dupas, por transdisciplinaridade, uma vez que o conjunto de tecnologias nano transpassa as mais diversas áreas do conhecimento, e através dessas disciplinas que se busca a compreensão da complexidade do tema, pois que "a transdisciplinaridade não procura o domínio sobre várias outras disciplinas, mas a abertura de todas elas àquilo que as atravessa e as ultrapassa" (CARTA DE TRANSDISCIPLINARIDADE, 1994).

A matéria em escala nanométrica sempre existiu naturalmente. Contudo, somente após alguns milhares de anos evoluindo o "homo sapiens" adequou seus microscópios para então observar esse nano universo e depois alterá-lo. O ser humano apenas agora está tendo condições científicas e técnicas para acessá-la (ENGELMANN; FLORES; WEYERMÜLLER, 2010, p. 17). E ao surtir a possibilidade de manipular nesta escala, tem-se uma das descobertas mais promissoras dos últimos tempos, visto que é permitido alterar a matéria em escala atômica, dando, então, a possibilidade para criação de coisas que seriam impossíveis em qualquer outra escala. "É assim que ocorre uma série de coisas novas que significam oportunidades completamente novas para design. Átomos na escala nonométrica possuem um comportamento diverso da escala grande (...) estaremos trabalhando com leis diferentes, e poderemos esperar fazer coisas diferentes. Podemos produzir de formas diferentes" (FEYNMAN, 1959)

É válido elucidar a distinção entre inovação e invenção, a fim de eliminar qualquer confusão acerca da temática, assim sendo, "uma invenção constitui uma proposta, projeto, modelo para um dispositivo, processo, produto, sistema novo ou aperfeiçoado. Enquanto inovação apenas se concretiza com a primeira transação comercial envolvendo aquele novo produto" (SCHULZ, 2006, p. 11). Ademais, salienta-se a colocação:

A nanotecnologia está emergindo como a próxima revolução tecnológica, com eventuais efeitos sobre todos os aspectos da vida. De especialista a estrategistas militares, há o consenso de que o crescimento da capacidade da construção 
molecular - manufatura molecular, fabricação molecular - mudará profundamente o mundo atual em que vivemos (ALVES, 2005).

Por representar um conjunto de tecnologias e ser uma inovação, logo se conclui que as nanotecnologias são uma inovação tecnológica. A inovação tecnológica ocorre quando "é resultado da aplicação de conhecimentos obtidos através da pesquisa científica aplicada a produtos ou processos de produção, com novas funcionalidades e efetivos ganhos de qualidade ou produtividade, resultando em maior competitividade" (MANUAL DA INOVAÇÃO). Portanto, a partir da segunda características das nanotecnologias, explicitada no conceito da ISO TC 229, qual seja, "o aparecimento de fenômenos dependentes de tamanho geralmente permite novas aplicações", se tem o cerne que sinaliza a inovação gerada por meio das nanotecnologias. Vale dizer, a escala nanométrica - representada pela notação científica de $10^{-9}$ - ocorrem modificações físico-químicas diferentes daquelas existentes em escalas maiores. Este detalhe, além de chamar a atenção aos riscos, destaca a inovação radical das nanotecnologias, pois as possibilidades de desenvolver novos produtos, com características inéditas, mostra o caráter inovador dos resultados obtidos na escala nano.

Toda transformação tem suas consequências, entre elas é interessante observar a mudança que acarretará no processo industrial. "Devido ao elevado grau de inovação conferido pelas mudanças em produtos e processos industriais gerados pelo avanço da Nanotecnologia deverá causar a obsolescência de diversos produtos e processos atualmente em uso." Isso expõe uma problemática que merece atenção, pois afim de "evitar que esse processo comprometa a competitividade da indústria brasileira, é necessário investir em ações que contribuam para a convergência da Nanotecnologia na geração de produtos, processos, serviços e patentes" (INSTITUTO INOVAÇÃO).

\section{Inovando o/no Direito}

Diante de todos os aspectos, uma coisa é certa: os efeitos da nanotecnologias, positivos ou negativos, serão suportados por nós, seres humanos e o meio ambiente; para tanto, é necessário interpretar esses aspectos e relacioná-los ao Direito. Ainda existe a ideia que o Direito "é basicamente um fenômeno de disciplina social de forma repressiva e 
punitiva", algo que se mostra absolutamente obsoleto, vez que a "própria sociedade alterouse, em sua complexidade, com o aparecimento de fenômenos novos", como os avanços tecnológicos. Ora, com o surgimento dessas transformações, o Direito, "como fenômeno marcadamente repressivo, tornou-se também e sobretudo um mecanismo de controle premunitivo" (FERRAZ JR, 2010, p. 62). Por conta disso, do Direito exigir-se-á outro conjunto de arcabouços normativos, propositalmente abertos, flexíveis, imprevisíveis, promotores e incentivadores de atitudes e comportamentos. Trata-se de uma efetiva transformação no modo de conceber o jurídico. Por isso, será necessária uma inovação no Direito, ou seja, um processo no interior da estrutura normativa. Desta forma, a fonte preponderante - a lei - deverá receber ao seu lado, outras fontes, as quais, de categoria subsidiária ou secundária, passarão ao primeiro plano, com sua compreensão/interpretação/aplicação concomitante com o texto legal. O resultado será obrigatoriamente filtrado pelo texto constitucional, assegurando-se a validade constitucional da decisão que será gerada.

Ao lado dessa operação, será fundamental inovar $\underline{o}$ Direito, como um processo externo, reposicionando-o como uma Ciência Humana e suas relações com as demais, além do seu papel com as Ciências Exatas. Do isolamento epistemológico ao diálogo transdisciplinar mirando na sociedade do conhecimento. Destarte, também estará em condições de reassumir o seu papel de orientador dos caminhos e planos democraticamente desenhados para o grupo social. Esta é a sua função precípua e não um mero corpo de regras punitivo-repressivas.

A explicitada transformação liga-se ao seguinte movimento: a ficção científica, na atualidade transporta-se ao mundo dos fatos, pois agora é possível criar máquinas nano que interagem com o meio externo e interno, tanto da matéria bruta como o meio biológico, entre esse meio destaca-se o corpo humano. Tornou-se possível imaginar um futuro onde as partículas nano cumpram funções preestabelecida com uma efetividade ainda inestimável. Por se tratar de uma inovação, a dimensão e a grandeza da pequeníssima escala, na qual agora é acessível a mais moderna aparelhagem tecnologia, não encontra-se delimitada. Em outras palavras, não se tem dados precisamente analisados pelos cientistas sobre a real dimensão do 
poder nano e suas consequências em um contato com o meio externo, fora do laboratório de pesquisa. A resposta satisfatória sobre até onde vai o poder dessa nova tecnologia ainda não existe; visto que os métodos de análise e pesquisa até o momento são os mesmos da manipulação em maior escala, o que significa ser inadequado para respostas precisas e seguras, "a maior parte da nanotecnologia continua sendo um conjunto de soluções em busca de um problema" (SCHULZ, 2006, p.62) Aponta-se um princípio fundamental para servir de base a toda pesquisa e aplicação de qualquer produto ou processo que envolva partículas nano, o princípio da precaução:

Configurado como verdadeiro princípio fundante e primário da proteção os interesses das futuras gerações, é ele que impõe prioritariamente e antecipadamente a adoção de medidas preventivas e justifica a aplicação de outros princípios, como o da responsabilização e da utilização das melhores tecnologias disponíveis (CANOTILHO, 2008, p. 6-9).

Esse princípio é a ideia norteadora do Direito Ambiental, e foi Consagrado na Conferência das Nações Unidas para o Meio Ambiente e o Desenvolvimento, reunida no Rio de Janeiro em 1992, além disso, tal princípio está presente em duas convenções internacionais, assinadas, ratificadas e promulgadas pelo Brasil, a Convenção sobre Diversidade Biológica e a Convenção Quadro das Nações Unidas sobre Mudança do Clima, não resta dúvida que tal princípio é direito positivo, no Brasil (AZEVEDO, 2008, p.133).

Todo esse avanço na área nanotecnologia transformou-se em objeto de fomentação mercantil agora é possível desenvolver produtos com outras características inéditas que parecem ser muito agradáveis ao consumidor. Diante dos aspectos apresentados, é cabível às empresas utilizadores dos nanomateriais, seja na produção ou no produto final, avaliar os possíveis riscos ao qual esse avanço tecnológico venha a acarretar; tanto no consumidor quanto ao meio ambiente.

Questões fundamentais preocupantes, como a da viabilidade de frear os avanços "nanotechs" afim de prevenir acidentes que possam ocorrer nessa interação não muito explorada entre meio ambiente e objetos manipulados na escala nano; o que parece tarefa árdua, uma vez que em todo mundo estão espalhadas empresas dedicadas a pesquisa e aplicação dessa nova tecnologia. Outro problema é a espera de fatos notáveis para a 
normalização, o que quer dizer, aguardar os resultados das pesquisas e das aplicações nesses produtos compostos de nanomateriais para somente depois tomar medidas que visam a regulamentação para fins preventivos. Não existem leis sobre nanotecnologia, o que existem são estudos, manuais e projeções.

É sabido que uma associação ou organização social é um conjunto de pessoas que em seu relacionamento mútuo reconhecem algumas regras como determinantes para seu agir (EHRLICH, 1932, p. 37) Salienta-se o dever de uma preocupação ética das corporações envolventes da Inovação - consoante com a teoria de Henry Etzkowitz - o que significa introduzir uma célula norteadora para com as demais entidades envolvidas nessa relação, uma quarta hélice. Pois caracterizarmos a tríplice hélice, nos moldes da teoria de Henry Etzkowitz, percebeu-se a despreocupação quanto ao teor ético e humano da movimentação das hélices, quer seja, a falta de uma medida que promova o mais sadio desenvolvimento para com a humanidade, frente as possíveis relações entre universidade, indústria e estado.

Um aspecto imutável do ser humano é a sua fragilidade e a limitação biológica como ser vivo, o que deve ser ao máximo respeitado em sua integridade pelos avanços de inovação, que deveriam ser automaticamente assimilados pelos cientistas, empresários e políticos, pois certo que esses fazem parte do grupo que seria afetado, positiva ou negativamente pelas consequências ditadas pelas inovações produzidas e consumidas. A fim de resguardar a dignidade humana e impedir que qualquer violação se instaure, é pertinente adequar a quarta hélice, como pano de fundo no movimento das três hélices, norteando não tão somente as suas ações como as suas consequências.

A quarta hélice deverá ser desenhada a partir do princípio da precaução (quando não há certeza científica sobre os riscos) e do princípio da prevenção (quando os riscos são conhecidos, adotando-se medidas concretas para evitar os efeitos negativos). No caso das nanotecnologias, aplicam-se, parcialmente, os dois princípios, eis que alguns riscos já são conhecidos, mas outros não. Assim, caberá valer-se de outro princípio, que corresponde à fusão de ambos: o princípio do "tão baixo quanto razoavelmente possível”. Vale dizer, os efeitos nocivos em relação ao ser humano e o meio ambiente deverão ser mantidos num nível 
razoavelmente mínimo, avaliado a partir de metodologias de análise construídos pela mediação entre as Ciências Humanas e Ciências Exatas.

\section{Conclusão}

O ser humano possui uma capacidade intelectual e criativa que tem se mostrado com amplitude sem registros na história recente. As nanotecnologias são um exemplo privilegiado disso. O desenvolvimento de equipamentos que viabilizem o acesso a esta escala e a produção de coisas novas formatam os contornos da chamada inovação radical.

O contexto assim delineado também exerce reflexos sobre o Direito. Serão necessários marcos regulatórios adequados e em condições de dar respostas jurídicas em tempo hábil e substancialmente sintonizadas com as novidades. Por isso, além de uma profunda reforma estrutural na concepção do jurídico, também deverão ser deixados de lado paradigmas como os da certeza, da previsibilidade e da segurança - marcas do positivismo legalista. No seu lugar, serão construídas soluções e respostas adaptadas e em condições de promover o acompanhamento do desenvolvimento econômico, social e científico da sociedade.

Por isso, o cenário da inovação, ainda presente especialmente no contexto acadêmico e industrial, deverá ganhar a formatação do jurídico, começando pelo seu ensino, espalhando-se pela sua interpretação e aplicação - dentro das possibilidades do círculo hermenêutico.

Por tais contornos, a pesquisa e o desenvolvimento do/no Direito, a partir do espectro da fenomenologia-hermenêutica, não poderão estar vinculados ao método: “[...] a compreensão é um jogo, não no sentido de que aquele que compreende se reserve o si mesmo como num jogo e se abstenha de tomar uma posição vinculante frente às pretensões que lhe são colocadas." O jogo representa os contornos da inovação, que vêm ao encontro do pesquisador, interpelando-o acerca das possibilidades negativas e positivas, provocando a tomada de uma decisão. “[...] Aquele que compreende já está sempre incluído num 
acontecimento, em virtude do qual se faz valer o que tem sentido." Por isso, não se poderá esquecer: “[...] no conjunto da nossa investigação evidencia-se que, para garantir a verdade, não basta o gênero de certeza, que o uso dos métodos científicos proporciona." Aqui o ponto fulcral que não se deverá perder de vista: o caráter científico das respostas não depende exclusivamente os contornos precisos prometidos pelo método. "Isso vale especialmente para as Ciências do Espírito [ou Ciências Humanas], mas não significa, de modo algum, uma diminuição de sua cientificidade, mas, antes, a legitimação da pretensão de um significado humano especial, que elas vêm reivindicando desde antigamente." No movimento da Revolução das Nanotecnologias chegou o momento de se valer estas características especiais das Ciências Humanas, dentre as quais se situa o Direito. "O fato de que, em seu conhecimento, opere também o ser próprio daquele que conhece, designa certamente o limite do 'método', mas não da ciência." Se propugna desenvolver o Direito, como um efetivo conhecimento científico, mas não necessariamente atrelado aos limites estreitos do método. “O que a ferramenta do 'método' não alcança tem de ser conseguido e pode realmente sê-lo através de uma disciplina do perguntar e do investigar, que garante a verdade" (GADAMER, 2002, p. 708-9, § 494). O perguntar e o investigar representam a explicitação das condições por meio das quais se dá a compreensão, na aproximação da précompreensão/compreensão/interpretação/aplicação, etapas não fracionadas do círculo hermenêutico, onde a linguagem indica a melhor resposta, orientada pela fala da tradição, da experiência, projetada no horizonte do agir e acontecer do ser humano.

\section{Referências}

\section{ABDI - AGÊNCIA BRASILEIRA DE DESENVOLVIMENTO INDUSTRIAL. Estudo} Prospectivo Nanotecnologia. Brasília: ABDI, 2010, Série Cadernos da Indústria ABDI, vol. XX.

AZEVEDO, F. (org.). As ciências no Brasil. Rio de Janeiro, RJ: Editora UFRJ, 1994. 2 v.

BERGER, Michael. Investing in nanotechnology stocks - golden opportunity or bad idea? Disponível em <http://www.nanowerk.com/spotlight/spotid=1328.php $>$ Acesso em 25/11/2011. (Postado em 25/01/2007).

BOBBIO, Norberto. Da Estrutura à Função: novos estudos de Teoria do Direito. Tradução de Daniela Beccaccia Versiani. São Paulo: Manole, 2007. 
CARTA DE TRANSDISCIPLINARIDADE. Disponível em: < HYPERLINK "http://www.caosmose.net/candido/unisinos/textos/textos/carta.pdf"www.caosmose.net/candid o/unisinos/textos/textos/carta.pdf> Acesso em 20/11/2011.

DICKEN, Peter. Mudança Global: mapeando as novas fronteiras da economia mundial. 5. ed. Tradução de Teresa Cristina Felix de Sousa. Porto Alegre: Bookman, 2010.

ENGELMANN, Wilson. Direito Natural, Ética e Hermenêutica. Porto Alegre: Livraria do Advogado Editora, 2007.

ENGELMANN, Wilson; FLORES, André Stringhi; WEYERMÜLLER, André Rafael. Nanotecnologias, Marcos Regulatórios e Direito Ambiental. Curitiba: Honoris Causa, 2010 .

ENGELMANN, Wilson. As nanotecnologias e a Inovação Tecnológica: a "hélice quádrupla" e os Direitos Humanos. In: Nanotecnologias: um desafio para o Século XXI, 2010, São Leopoldo. Anais do Seminário. São Leopoldo : Editora Casa Leiria, 2010. v. 1CD. p. 148189.

ENGELMANN, Wilson. Nanotechnology, Law and Innovation. Saarbrücken, Germany: LAP LAMBERT Academic Publishing GmbH \& Co. KG, 2011.

EHRLICH, Eugen. Fundamentos da sociologia do direito. Brasília: Universidade de Brasília, 1986. 388 p.

FERRAZ JUNIOR, Tercio Sampaio, Introdução ao estudo do direito: técnica decisão, dominação. 6. ed. São Paulo: Atlas, 2010.

FEYNMAN, Richard P. There's Plenty of Room at the Bottom: an Invitation to Enter a New Field of Physics. Palestra proferida em 29 de dezembro de 1959, por ocasião da Reunião Anual da Sociedade Americana de Física, no California Institute of Technology (Caltech). Disponível em: <http://www.zyvex.com/nanotech/feynman.html> Acesso em 27/11/2011.

FÓRUM DE COMPETITIVIDADE em Nanotecnologia. Disponível em: $<$ http://www.mdic.gov.br//sitio/interna/interna.php?area=3\&menu=2469 $>$ Acesso em 26/11/2011.

FREEMAN, Chris e SOETE, Luc. The Economics of Industrial Innovation. 3. ed. Massachusetts: MIT Press, 2000.

GADAMER, Hans-Georg. Verdade e Método: traços fundamentais de uma hermenêutica filosófica. 4. ed. Tradução de Flávio Paulo Meurer. Petrópolis: Vozes, 2002.

HEIDEGGER, Martin. Ser e Tempo. 12. ed. Tradução de Marcia Sá Cavalcante Schuback. Petrópolis: Vozes, 2002, Parte I. 
INSTITUTO INOVA. Disponível em: 〈http://www.institutoinova.org.br/index.php/inova $>$ Acesso em 26/11/2011.

INSTITUTO INOVAÇÃO: Disponível em: <http://inventta.net/radarinovacao/categoria/artigos-estudos/> Acesso em 19/11/2011.

ISO TC 229. Disponível em:

<http://www.iso.org/iso/standards_development/technical_committees/list_of_iso_technical_c ommittees/iso_technical_committee.htm?commid=381983> Acesso em 19/11/2011.

MANUAL DE FRASCATI. Disponível em $<$ http://www.reppittec.org.br/ArquivosUpload/1/File/Manual_de_Frascati.pdf $>$ Acesso em 26/11/2011.

MANUAL DE OSLO. Disponível em $\langle$ http://www.finep.gov.br/imprensa/sala_imprensa/manual_de_oslo.pdf $>$ Acesso em 26/11/2011.

MCTI - Ministério da Ciência, Tecnologia e Inovação. Disponível em: <http://www.mct.gov.br/index.php/content/view/105.html> Acesso em 26/11/2011.

MDIC - Ministério do Desenvolvimento, Indústria e Comércio Exterior. Disponível em: < http://www.desenvolvimento.gov.br/sitio/interna/index.php?area=3> Acesso em 25/11/2011.

NEUTZLING, Inácio; ANDRADE, Paulo Fernando Carneiro de (Org.). Uma sociedade póshumana: possibilidades e limites das nanotecnologias . São Leopoldo: UNISINOS, 2009. 203 p.

PEREIRA, José Matias; KRUGLIANSKAS, Isak. Gestão de Inovação: A lei da Inovação Tecnológica como ferramenta de apoio às políticas industriais e tecnológicas no Brasil. RAEeletrônica, v. 4, n. 2, Art. 18, jul./dez. 2005.

PRODANOV, Cleber. Vivendo a Inovação. Disponível em:

$<$ http://www.sct.rs.gov.br/principal.php?menuSelecionado=artigo\&cod=16> Acesso em: $20 / 11 / 2011$.

SCHULZ, Peter Alexander Bleinroth. A encruzilhada da nanotecnologia: inovação, tecnologia e riscos. 1. ed. Rio de Janeiro: Vieira \& Lent, 2009. 125 p. (Ciência no bolso ; Nanotecnologia e sociedade )

TIGRE, Paulo Bastos. Gestão da Inovação: a Economia da Tecnologia no Brasil. $4^{\text {a }}$ reimpressão. Rio de Janeiro: Elsevier, 2006. 